\title{
Photovoltaic Maximum Power Point Grid Connected based on Power Conditioning Technique Employing Fuzzy Controller
}

\author{
M. Bakkar, M. Abdel-Geliel and M. Abo zied \\ Department of Electrical and Control Engineering \\ AAST, Alexandria, Egypt \\ E-mail: $\underline{\text { mos_bico@yahoo.com, maelgeliel@yahoo.com, mca2ao@gmail.com }}$
}

\begin{abstract}
Most of the Maximum Power Point Tracking (MPPT) techniques for Photovoltaic (PV) system utilize the PV voltage and current measurements. An MPPT technique for grid connected PV system, which does not require PV measurements, is proposed and implemented. This approach utilizes post-stage inverter current instead of calculating solar array power. This approach is called Power Conditioning System (PCS). PCS requires a searching engine to track the Maximum Power Point (MPP) of the PV system. Fuzzy logic is one of the most powerful MPPT engines, which has high performance and robustness. Therefore, Fuzzy Logic Control (FLC) method is implemented and compared with the other methods. Moreover a proposed method that combines FLC with PCS is designed and tested. In addition, the PCS employing an adaptive fuzzy controller is also designed in order to enhance system performance and robustness. To compare between classical MPPT techniques and the proposed techniques, simulations of overall system using different MPPT techniques are performed. The simulation results are analysed. Moreover, Practical implementation is carried out to validate the simulation results.
\end{abstract}

\section{Key words}

Photovoltaic (PV), Maximum power point tracking (MPPT), Module Integrated Converter (MIC), PV power conditioning system (PCS) and Fuzzy Logic Controller (FLC).

\section{Introduction}

The highly increasing demand of energy requires the wide usage of alternative resources in particular renewable such as PV and wind. PV system is currently applied extensively due to the technological and economical progress of PV production. PV system is connected to the load directly as standalone system or indirectly through electric grid, which is called grid connected PV system. The grid connected system is preferred if there are more than one resource of electric energy. Therefore, this work addresses the control and operation of MPPT of PV grid connected system.

There are two topologies used to connect the PV with the grid: two stages and single stage PV system [10]. Since two-stage PV energy conversion system offers an additional degree of freedom in the operation of the system when compared with the one-stage configuration, it is selected in this work. The analysis of a single phase multi stage grid connected photovoltaic system concentrates on the topology study of the photovoltaic module integrated converters. Therefore, by including a dc-dc converter between the PV array and the inverter connected to the electric grid, various control objectives are possible to track concurrently with the PV system operation [1].

Since the generated power of PV system varies according to environmental condition, it is necessary to operate the PV at maximum power condition by using MMPT techniques. Meany MPPT techniques have been scattered in literature. MPPT based on PCS using FLC is introduced in [2] and [10].

The single phase multi stage grid connected system being modelled is shown in Fig. 1. It consists of a PV array followed by step up stage feeding a current controlled voltage source inverter that feeds current into the single phase grid and local single phase loads [3]. Where: $V_{\mathrm{pv}}, \mathrm{I}_{\mathrm{pv}}, \mathrm{Q}_{\text {flyback}}, \mathrm{V}_{\text {ref_DC }}, \mathrm{V}_{\mathrm{DC} \_ \text {Link }}, \mathrm{V}_{\text {Grid }}, \mathrm{V}_{\mathrm{AB}}$ and $\mathrm{i}_{\text {Grid }}$ are $\mathrm{PV}$ voltage, $\mathrm{PV}$ current, DC link reference voltage, DC link voltage Grid voltage, Inverter voltage and Grid current respectively.

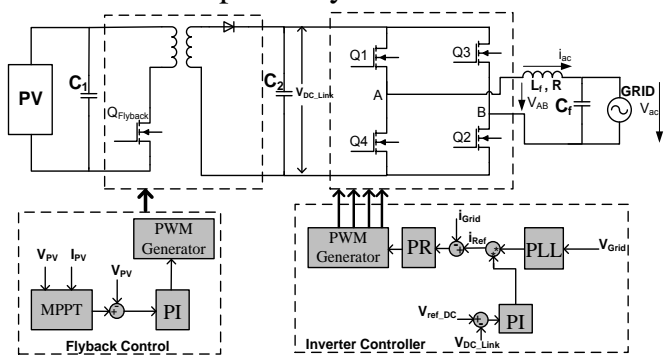

Fig. 1 Overall system modelling including control signals.

As shown in Fig. 1, DC-DC converter output is connected to the dc bus of the DC-AC converter. The DC-DC converter produces a chopped output voltage and therefore controls the average DC voltage relation between its input and output aiming at continuously so the characteristic of the PV system and the DC-AC converter be matching. The flyback boost DC/DC converter is made to drains the power from the PV solar cell array and supplies the DC link capacitor with a maximum power point tracker obtained from the MPPT controller [4]. The flyback transformer provides isolation and also the voltage ratios are multiplied by turn's ratio. Figure 2 shows the signals in every part of the system [5]-[6].

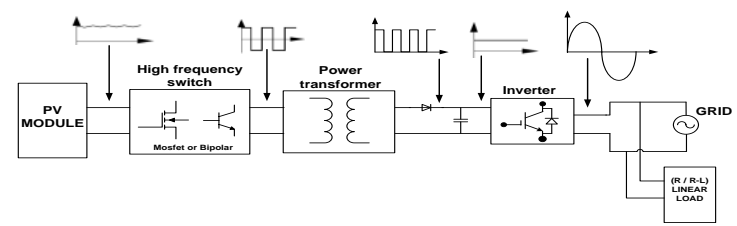

Fig. 2 Signals shapes in the whole system. 
In order to track the time varying MPP of the solar module due to operating conditions of insulation and temperature [7] and loading, this paper proposes an MPPT and compares it with different MPPT control techniques. The proposed MPPT technique is based on PCS employing FLC and adaptive. The purpose of the proposed technique is to enhance the overall performance and robustness of single phase PV grid connected system for different operating conditions and loading.

The paper is organized as follow: the system configuration and problem definition is introduced in section 1; section 2 illustrates using fuzzy logic controller as stand-alone MPPT technique; section 3 explains the proposed technique; section 4 illustrates the simulation results of the proposed system in comparison with other techniques; to validate the simulation results, the proposed technique is practically implemented in section 5; finally, the work results and analysis is highlighted in the conclusion.

\section{MPPT using Fuzzy Logic Controller}

It is known that the output power of PV module varies with weather conditions [7]. Therefore, real-time MPPT control, for extracting maximum power from the PV panel, becomes indispensable in PV systems [8]-[9].

The input variables for MPPT technique, as illustrated in Fig. 1, are the PV voltage and current. Most of MPPT techniques tracks the maximum power by detecting the operating points that satisfies " $d P_{P V} / d V_{\mathrm{PV}}=0$ "; where $P_{P V}$ and $V_{P V}$ are the PV power and voltage.

Using FLC as an MPPT gains several advantages of better performance, reliability and simple design [10], [12]. The FLC MPPT controller has two inputs and one output. The two FLC input variables are the error " $E$ " and change of error " $C E^{\prime \prime}$ at sampled times $j$ [13]-[14]. The FLC input variables can be computed as:

$P_{P V}=V_{P V} * I_{P V}$

$E(j)=\frac{P_{P V}(j)-P_{P V}(j-1)}{V_{P V}(j)-V_{P V}(j-1)}$

$C E(j)=E(j)-E(j-1)$

Where $P_{P V}, I_{P V}, V_{P V}$ are the PV power, current and voltage respectively at instant $j$.

Figure 3 shows the classical MPPT based on FLC alone of the given configuration [10]. The $E$ and $C E$ are deduced from the sensed PV voltage (V_PV) and current (I_PV) in SUB SYSTEM block in Fig. 3 according to eq. (1) to eq. (3). After that the deduced $E$ and $C E$ is manipulated in FLC to generate the PWM of the fly-back boost converter. The FLC parameters (number of membership functions and their types, rule base, fuzzification, etc.) are addressed in details in [10].

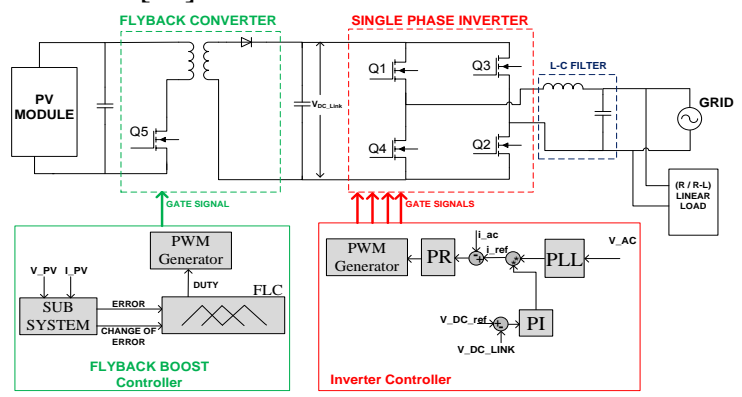

Fig. 3 Classical MPPT based on FLC.

\section{Proposed MPPT based on Power Conditioning Technique}

Different MPPT techniques are discussed in details in [10]. This section explains the proposed MPPT based on PCS and FLC.

\section{A. Power Conditioning Method}

This scheme has economical advantage in addition to the simplicity of implementation because it doesn't need to sense the PV voltage and current to compute the PV power in order to control the DC-DC converter but it requires only measuring the inverter current or its corresponding signal. These approaches use the DC-link voltage error, which represent the inverter current variation, to control the duty of the fly-back boost converter, of the used configuration shown in Fig. 4, which is proportional to the solar module output power for the MPPT [10]. Figure 4 shows the Photovoltaic Power Conditioning System with control circuits. The equation of the error signal is described as:

$V_{\text {Error }}=K_{p}\left(V_{D C_{\_} \text {Link }}-V_{\text {ref__ } D C}\right)+\frac{K_{i}}{S}\left(V_{D C_{\_} \text {Link }}-V_{\text {ref_DC } D C}\right)(4)$

The concept of PCS depends essentially on making the DC-link voltage is constant. By fixing the DC-Link, the input current of the inverter is directly proportional to the solar module output power. On the other side, the output voltage of inverter $\mathrm{V}_{\mathrm{AB}}$ (Fig. 1) depends on the input voltage of the inverter $\mathrm{V}_{\mathrm{DC}_{-} \text {Link }}$, and then by controlling the voltage of DC link, the inverter output power can be controlled.

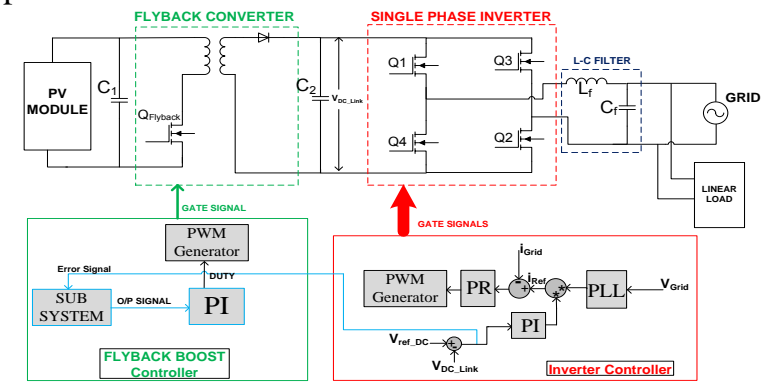

Fig. 4 Photovoltaic Power Conditioning System with control circuits.

The main benefit of this method is that it performs MPPT without the solar module power calculation. This simple operation principle offers cost competitiveness and compactness of size because it reduces the measured signals [11]. However, it has considerable limitations, which may possibly be summarized in: 1) it has slower response than classical FLC and incremental conductance; 2) it has steady state error; and 3) the system oscillates around steady state value [10].

\section{B. Proposed Power Conditioning Method using Fuzzy Logic Controller}

In order to overcome the limitations of MPPT based on PCS, a combination of FLC and PCS is suggested. In this method the FLC is used to determine the duty cycle for the fly-back converter as in classical MPPT based on FLC but the main difference is the input variable of FLC. The input for FLC, in this case, is V_err, which comes from the voltage loop in the inverter controller [10]. This 
method gives faster response than PCS alone, and at the same time, it doesn't require to know directly PV data. Moreover, it reduces the control signals used in the system. Figure 5 shows the configuration of PCS based on FLC [15]-[17].

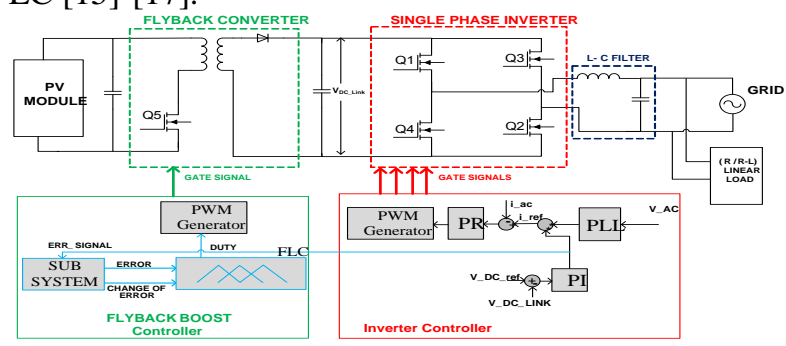

Fig. 5 Proposed system for PCS using FLC.

\section{Proposed Power Conditioning Method using Adaptive Fuzzy Logic Controller}

This method is used to enhance the performance and robustness of the PCS based on FLC. It depends mainly on adapting the FLC by adding or scaling the fuzzy output according to the current situation. Figure 6 illustrates the proposed technique. One of adapting FLC is addressed in [18], which adapts FLC according to the value open circuit voltage of the PV. The main drawbacks of this method are: 1) it needs more voltage transducer to measure the open circuit voltage; and 2) it requires disconnecting the PV to measure the Voc in order to modify the FLC parameters.

Since the deviation of open circuit voltage of PV for different atmospheric condition is relatively small, it is not necessary to measure the open circuit voltage during operation. The suggested adaptation technique does not require measuring the open circuit voltage but it requires comparing the DC voltage deviation with the nominal deviation of the open circuit voltage at normal condition. In this method, the additional feed forward loop may enhance the behavior by adapting the output of nominal FLC. The output duty cycle of FLC is biased by a certain amount depending on the error signal of the DC link voltage and the nominal PV open circuit voltage (Voc) as shown in Fig. 6 [19]. The purpose of the dead band is to operate the part of the adaptive fuzzy only when the signal is far away from the desired signal. According to the following equation:

$D(n)=D_{f}(n)+\alpha * g\left(k * V_{O C}-V_{P V}(n)\right)$

Where $D$ is the current duty cycle, $D_{f}$ is the fuzzy output duty cycle, $g$ is the adaptation function it is a linear function with dead band $(\Delta v), k$ is the fractional open circuit voltage ration, $\alpha$ is the adaptation parameter, $n$ is the sample number, and $V_{O C}$ and $V_{p v}$ are the nominal open circuit and PV voltages respectively.

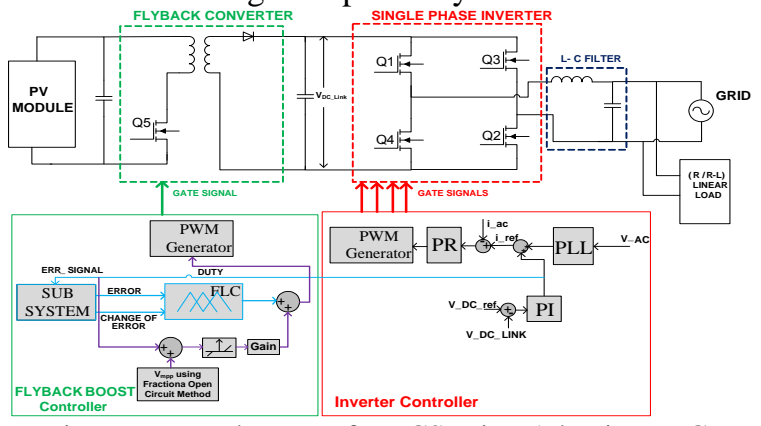

Fig. 6 Proposed system for PCS using Adaptive FLC.

\section{Simulation Results}

In order to investigate the effectiveness of the proposed model and control algorithms of the signal phase grid connected PV system, a group of simulations results has been presented using Simulation Power Systems of MATLAB / SIMULINK environment.

The system parameters for PV module KYOCERA KC200GT used in simulation are: the power, voltage and current at maximum power point are $200 \mathrm{~W}, 26.3 \mathrm{~V}$ and 7.8 A, respectively. Figure 7 shows the PV curve for the chosen PV module under different weather conditions.

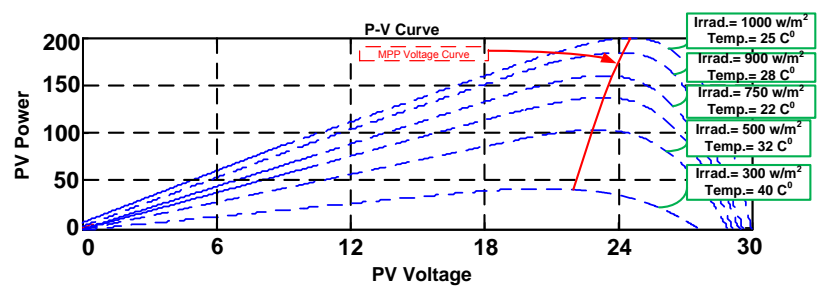

Fig. 7 PV curve for KYOCERA KC200GT PV under different weather conditions

Figures 8-11 show the changes in PV current, PV voltage, DC link voltage, grid current and load current for the same load when the condition of irradiation and temperature are changes in case of fuzzy, incremental conductance, PCS and PCS using FLC control methods respectively.

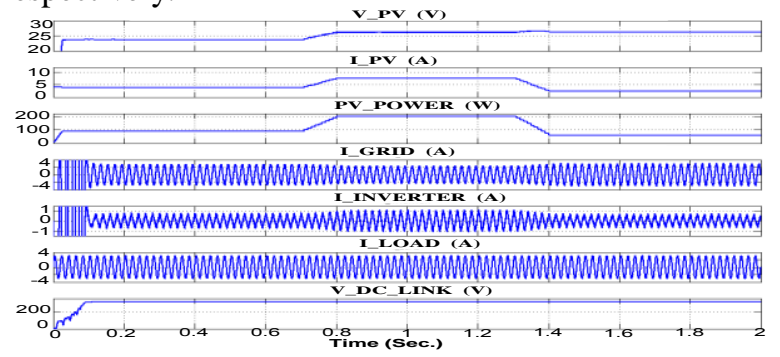

Fig. 8 Simulation Result for PV current, PV voltage, DC link voltage, grid current and load current with $900 \mathrm{~W}$ loads with (fuzzy controller).

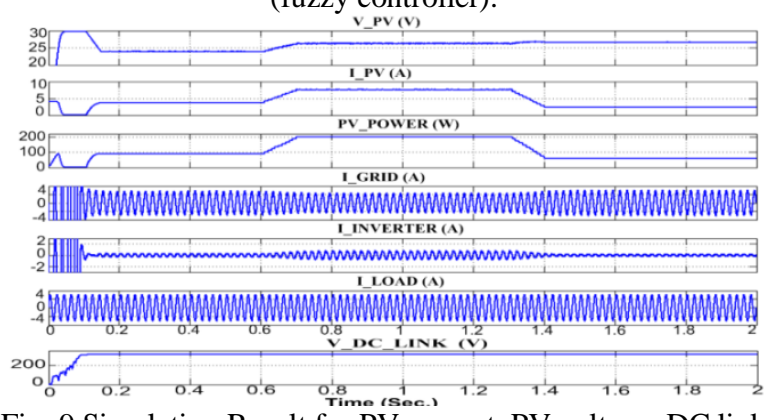

Fig. 9 Simulation Result for PV current, PV voltage, DC link voltage, grid current and load current with $900 \mathrm{~W}$ loads with (incremental conductance control).

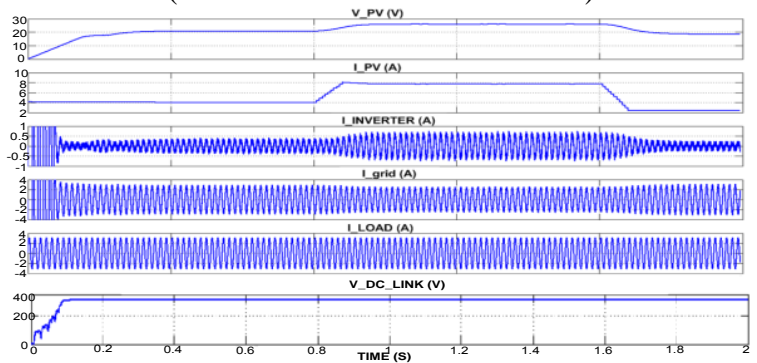

Fig. 10 Simulation Result for PV current, PV voltage, grid current and load current with $900 \mathrm{~W}$ loads with (power conditioning system control). 


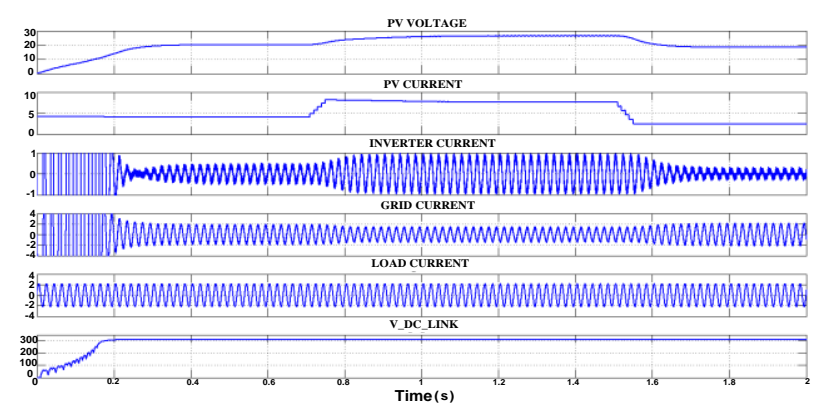

Fig. 11 Simulation Result for PV current, PV voltage, grid current and

load current with 900W loads with (PCS using FLC).

The results show that FLC has the fastest respond for any change in weather conditions, but it use more control signals than PCS. And for the incremental conductance method the control signals is the same with FLC but the response is slower. So for the applications needs fast response the FLC is recommended but the cost will increase, while for other applications PCS will be more recommended because it has used less control signals and that means low cost. Table I shows the difference between MPPT control techniques at insulation $=1000 \mathrm{w} / \mathrm{m}^{2}$ and temperature $=25 \mathrm{C}^{\circ}$.

At the same time, the results show the effect of weather condition on the PV power and inverter power. Also, it shows the effect on the load power, and the cases when the inverter feed the grid or absorbs power from it.

Figure 12 shows the PV voltage using PCS, PCS using FLC and PCS using Adaptive FLC. The graphs show that PCS using Adaptive FLC has the fastest response in compare to the other methods. But, there is a small overshooting on the MPP voltage due to the use of fractional open circuit voltage, as shown in Table I. Figures 13 -16 show the PV power, DC Link power, inverter power, grid power and load power in case of incremental conductance, FLC, PCS and PCS using FLC. The results show that, FLC has the fastest response and PCS has the slowest response because it depends on the signal comes from inverter controller. PCS using FLC is faster and smoother than PCS without FLC.

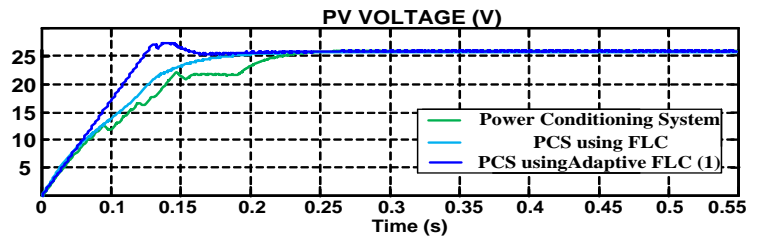

Fig. $12 \mathrm{PV}$ power at the same weather condition (PCS, PCS using FLC and PCS using Adaptive FLC)

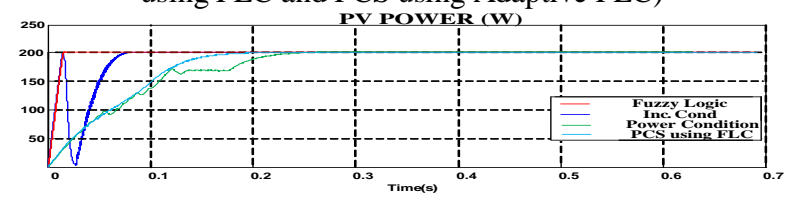

Fig. $13 \mathrm{PV}$ power at the same weather condition (incremental conductance, FLC, PCS and PCS using FLC)

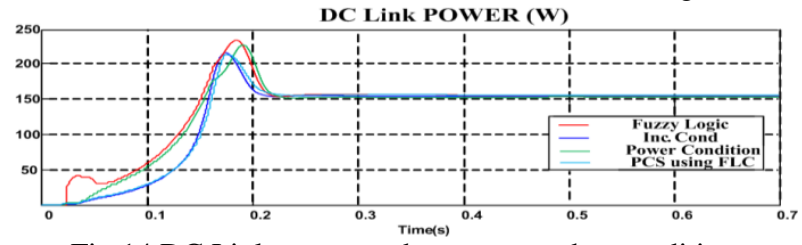

Fig.14 DC Link power at the same weather condition (incremental conductance, FLC, PCS and PCS using FLC)

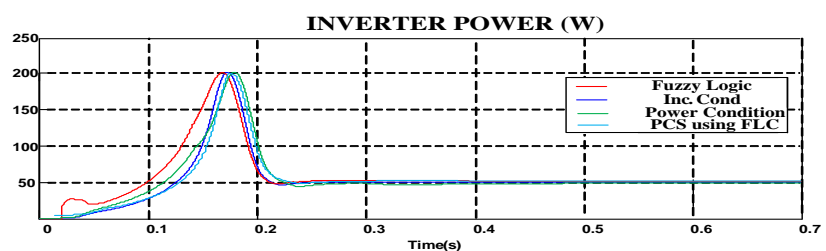

Fig. 15 Inverter power at the same weather condition (FLC, PCS and PCS using FLC)

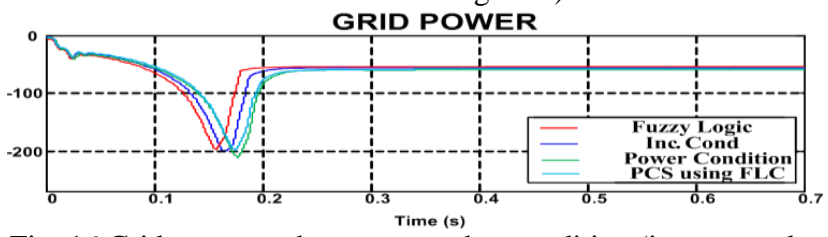

Fig. 16 Grid power at the same weather condition (incremental conductance, FLC, PCS and PCS using FLC)

Table I shows the comparison between chosen techniques.

Table I: comparison between chosen techniques results

\begin{tabular}{|c|c|c|c|c|c|}
\hline $\begin{array}{c}\text { Control } \\
\text { System }\end{array}$ & $\begin{array}{c}\text { Max. } \\
\text { Oversh- } \\
\text { oot }(\%)\end{array}$ & $\begin{array}{c}\text { Peak } \\
\text { Time } \\
(\mathrm{Sec})\end{array}$ & $\begin{array}{c}\text { Settli- } \\
\text { ng } \\
\text { Time } \\
(\mathrm{Sec})\end{array}$ & $\begin{array}{c}\text { Oscillat } \\
\text {-ions } \\
(\text { Volt })\end{array}$ & $\begin{array}{c}\text { Steady } \\
\text { State } \\
\text { Error } \\
(\text { Volt })\end{array}$ \\
\hline $\begin{array}{c}\text { Incremental } \\
\text { Conductanc } \\
\text { e }\end{array}$ & $24.9 \%$ & 0.045 & 0.11 & $\begin{array}{c}\text { Slight } \\
(0.3)\end{array}$ & NO \\
\hline Fuzzy & -- & -- & 0.015 & None & NO \\
\hline PCS & $0.5 \%$ & 0.006 & 0.27 & $\begin{array}{c}\text { Slight } \\
(0.25)\end{array}$ & $\begin{array}{c}\text { YES } \\
(0.3)\end{array}$ \\
\hline $\begin{array}{c}\text { PCS using } \\
\text { FLC }\end{array}$ & $0.5 \%$ & 0.002 & 0.2 & $\begin{array}{c}\text { Slight } \\
(0.1)\end{array}$ & $\begin{array}{c}\text { YES } \\
(0.22)\end{array}$ \\
\hline $\begin{array}{c}\text { PCS using } \\
\text { Adaptive } \\
\text { FLC }\end{array}$ & $9 \%$ & 0.001 & 0.165 & $\begin{array}{c}\text { Slight } \\
(0.05)\end{array}$ & $\begin{array}{c}\text { YES } \\
(0.15)\end{array}$ \\
\hline
\end{tabular}

The results show that the FLC has the fastest response and there is no oscillation but it need more control signals to measure PV voltage and current. Also, PCS, PCS using FLC and PCS using Adaptive FLC have slower response but at the same time they have lower control signals than FLC because it does not require any information about PV module.

\section{Practical Results}

A laboratory prototype for the system is implemented to verify the proposed compensation technique and the simulation results experimentally. Figure 17 shows hardware setup; a DSP is used to implement MPPT techniques. The DSP computes the control signals of the Flyback converter. The system parameters for PV module SHARP NE-80EJEA used in practical work are: the power, voltage and current at maximum power point are $80 \mathrm{~W}, 18.4 \mathrm{~V}$ and $4.3 \mathrm{~A}$, respectively. The measurements signals are $\mathrm{I}_{\mathrm{PV}}, \mathrm{V}_{\mathrm{PV}}$ and $\mathrm{V}_{\mathrm{DC}}$; where: $\mathrm{I}_{\mathrm{PV}}$ is the PV current, $\mathrm{V}_{\mathrm{PV}}$ is the PV voltage and $\mathrm{V}_{\mathrm{DC}}$ is the DC link voltage.

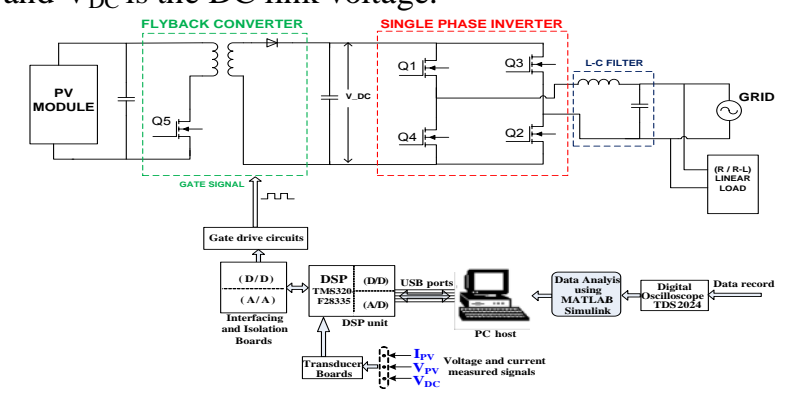

Fig. 17 Practical system setup 
Figure 18 shows the identified P-V curves of PV module under different weather condition for both practical and theoretical work.

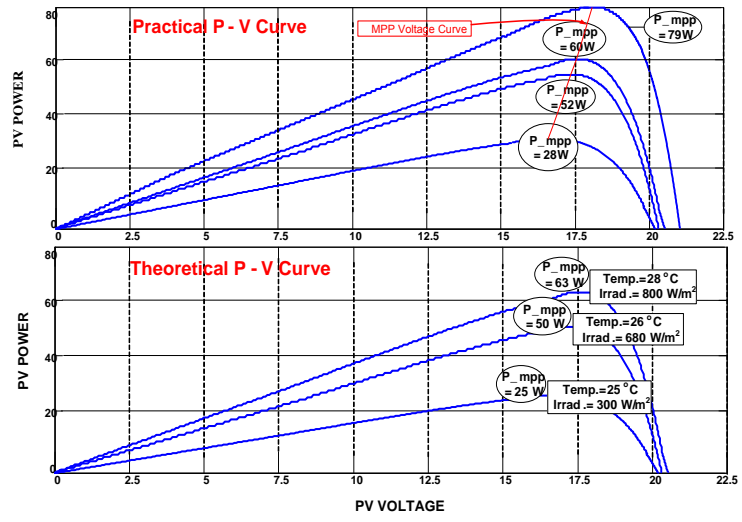

Fig. 18 Curves of PV module under different weather condition (Practical and Theoretical)

As shown in Fig. 19 the practical and theoretical $\mathrm{P}_{\mathrm{mpp}}$ signals are presented at 48 Watt at temperature $=26{ }^{\circ} \mathrm{C}$ and irradiation $=680 \mathrm{~W} / \mathrm{m}^{2}$. It is noted from P-V curve that, at this weather conditions, the voltage at MPP is nearly 16.5 V.

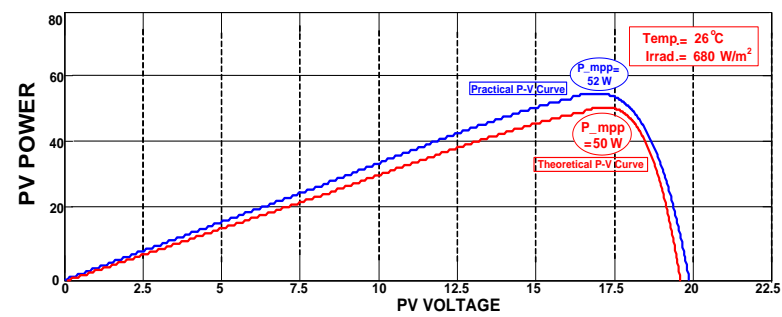

Fig. 19 Curve of PV module at 50 Watt (Practical and Theoretical) with temperature and irradiation approximately 26 ${ }^{0} \mathrm{C}$ and $680 \mathrm{~W} / \mathrm{m}^{2}$

\section{A. Validation of incremental conductance method}

Figure 20 shows the $\mathrm{V}_{\text {mpp }}$ signal measured by DSP at different weather condition for incremental conductance control method. The results for the incremental conductance method show that the system can get the maximum power from PV at this point as shown in Fig. 19.

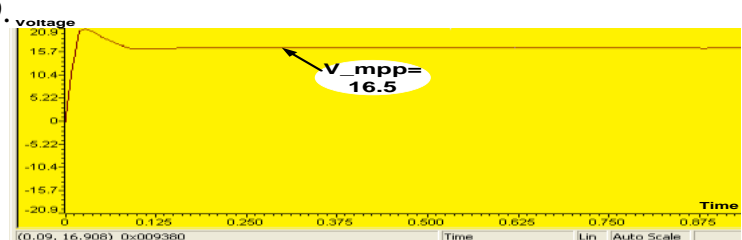

Fig. LU MPP Voltage with incremental conductance method measured by DSP at different weather condition

The results show that, the MPP voltage is 16.5 Volt, this result approximately is the same result that has been obtained from P-V curve at nearly $50 \mathrm{~W}$. Also, we can measure the MPP voltage by DSP to see the changes at the beginning of incremental conductance algorithm. The reading values stored in memory, and then it can be ploted against the time. Figure 20 shows the overshooting that has been happened in incremental conductance method.

Figure 21 shows the comparison between $\mathrm{V}_{-}$mpp signals practical and simulation for incremental conductance control method.
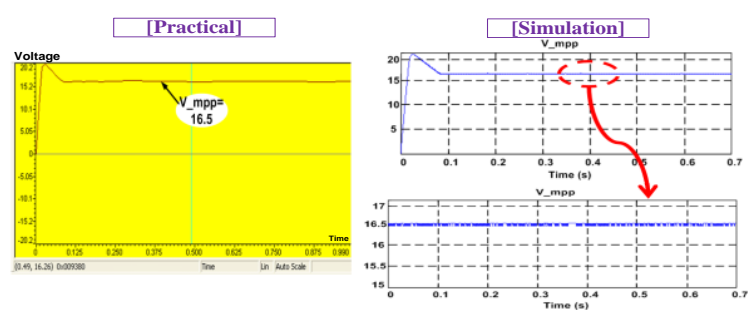

Fig. 21 MPP Voltage with incremental conductance method measured by DSP and measured from SIMULINK

\section{B. Validation of FLC and PCS using FLC methods}

The practical $\mathrm{V}_{\text {_mpp }}$ signal is presented at 52 Watt. As seen in Fig. 19 the voltage at MPP increases to approximately $16.9 \mathrm{~V}$.

Figures 22-23 show the $\mathrm{V}_{-}$mpp signals measured by LV.25P transducer and DSP for FLC and PCS using FLC and the comparison with simulation results. Results for FLC show that there is no overshooting and the system is faster than incremental conductance. For PCS using FLC the system is slower and there is no overshooting, but also the control measurements signals are fewer because this method do not need to get any information from PV module. For FLC and incremental conductance they need to read the current and voltage of PV module.
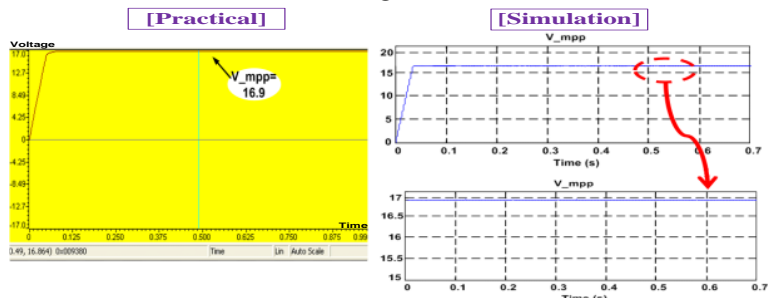

Fig. 22 MPP Voltage with FLC method measured by DSP and measured from SIMULINK

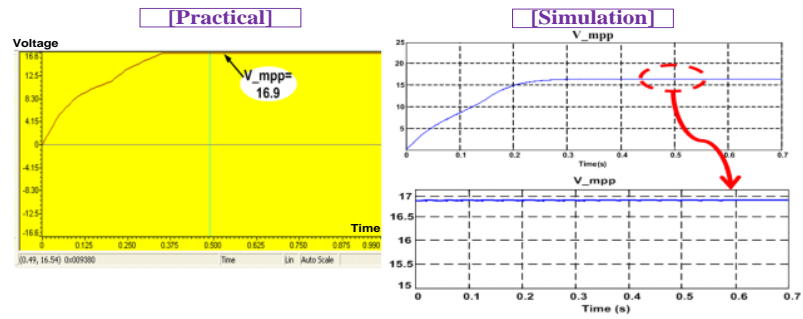

Fig. 23 MPP Voltage with PCS using FLC method measured by DSP and measured from SIMULINK

\section{Validation of injected active power}

The capacitor voltage, $V_{D C}$ is regulated at $160 \mathrm{~V}$. The capacitors voltage balance is almost achieved. This emphasizes the controller effectiveness. The changes in DC Link voltage (when the weather condition changes) are approximately between 159 161 V. Figure 24 shows inverter voltage for PCS using FLC, in practical and simulation. The output of the inverter is $215 \mathrm{rms}$ voltage, and also the grid voltage.

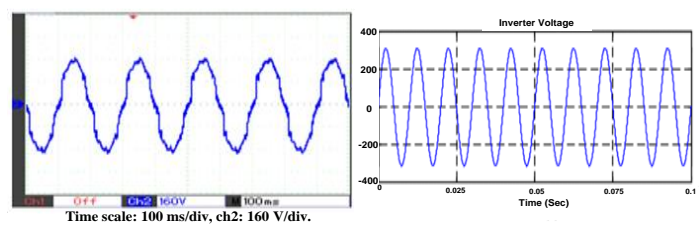

Fig. 24 Inverter Voltage (Practical and Simulation) 


\section{CONCLUSIONS}

A robust and fast MPPT technique is essential for a PV system to overcome the environmental condition and load variation and to achieve maximum power generation. Hence, MPPT techniques based on PCS employing FLC and adaptive FLC are proposed. The proposed techniques are simulated and compared with two conventional techniques, which are Incremental conductance and classical FLC. Moreover, four of the studied MPPT techniques (FLC, Incremental Conductance, PCS and combined FLC with PCS) have been implemented practically. In addition, an additional controller is implemented in order to achieve the synchronization to the grid and to perform the power management between the system and the electrical grid.

A comparison between the techniques has been carried out to demonstrate the advantages and limitations of each technique; it is clear that FLC is more robust and fast however it needs to measure the PV voltage and current. On the other side MPPT based on PCS is the cheapest and simplest technique but it gives slow response. In order to obtain the advantages of each method, a proposed MPPT, which combine PCS with FLC, is recommended. Moreover, to optimize the performance of the proposed MPPT, a combination of PCS with adaptive FLC is preferred.

The simulation analysis results is insured by and experimental validation. The robustness of the proposed techniques with respect to shielding effect should be addressed in the future.

\section{References}

[1] T. Shimizu, O. Hashimoto, and G. Kimura, "A Novel High Performance Utility-Interactive Photovoltaic Inverter System.” IEEE Trans. Power Electron, vol. 18, no. 2, Feb. 2003, pp. 704-711.

[2] A. Paul and A. Thomas, "Low Cost Stand-alone Renewable Photovoltaic Wind Energy Utilization Schemes Solar Energy", 2006 Oklahoma Conference, University of Georgia, USA, vol. 15, no. 5, 2006, pp. 14-21.

[3] H. El-helw, M. Hassanien, H.A. Ashour, "Maximum power point tracking for irregular irradiance of a photovoltaic array", in Environment and Electrical Engineering (EEEIC), 12th International Conference on Wroclaw, Poland, 5-8 May 2013, , pp. 52 - 57.

[4] E. Duran, J. Sidrach-de-Cardona, M. Galan and J.M.Andjar "Comparative Analysis of Buck-Boost Converters Used to Obtain I-V Characteristic Curves of Photovoltaic Modules", IEEE Power Electronics Specialists Conference, Rhodes, 15-19 June 2008, , pp. 2036 - 2042.

[5] H.Sugimoto et al., "A New Scheme for Maximum Photovoltaic Power Tracking Control," in 1997 PCCNagaoka Proc., Nagaoka, Japan, Vol.2, 3-6 Aug 1997, , pp.691-696.

[6] Chilachava, David, D. Kranzer and J. Thoma, "A highly efficient DC-DC-converter for medium-voltage applications", Energy Conference (ENERGYCON), Croatia, May 2014, pp. $127-131$.

[7] M. Matsui et al. , "New MPPT Control Scheme Utilizing Power Balance at DC Link Instead of Array Power Detection," in 2000 IEEJ IPEC-Tokyo Proc., Tokyo, Japan, Vol.1, pp. 164-169, 2000.
[8] Trishan Esram, Patrick L. Chapman, "Comparison of Photovoltaic Array Maximum Power Point Tracking Techniques," IEEE Trans. on Energy Conversion, Vol.22, no.2, June 2007, pp.439-449.

[9] G.M.S. Azevedo, M.C. Cavalcanti, and K.C. Oliveira, "Evaluation of Maximum Power Point Tracking Methods for Grid Connected Photovoltaic Systems," IEEE Power Electronics Specialists Conference, June, 2008, pp: 14561462.

[10] M. Bakkar, M. Abd el geliel and M. Abo zeed "Control of Photovoltaic Grid Connected Using Different Control Strategies" $22^{\text {nd }}$ Mediterranean Conference on Control and Automation (MED), 14(2), Italy, June 2014, pp. 710-715.

[11] H. S. Bae, J. H. Park and B. H. Cho "New Control Strategy for 2-stage Utility-Connected Photovoltaic Power Conditioning System with a low cost digital processor", Electronics Specialists Conference, PESC '05. IEEE $36^{\text {th }}$, 2005, pp.7803-9033.

[12] M.S. Khireddine, M.T. Makhloufi, Y. Abdessemed, and A. Boutarfa, "Tracking power photovoltaic system with a fuzzy logic control strategy," Computer Science and Information Technology (CSIT), 6th International Conference, March 2014, pp. $42-49$.

[13] H.E.A. Ibrahim, and M. Ibrahim, " Comparison Between Fuzzy and P\&O Control for MPPT for Photovoltaic System Using Boost Converter", Journal of Energy Technologies and Policy, Vol.2, no.6, 2012, pp. 22243232.

[14] P. Aurobinda, M. K. Pathak, and S. P. Srivastava, "Fuzzy Intelligent Controller for The Maximum Power Point Tracking of a Photovoltaic Module at Varying Atmospheric Conditions", Journal of Energy Technologies and Policy, vol.1, no.2, 2011, pp.18-27.

[15] M. Ajaamoum, M. Kourchi, R. Alaoui, and L. Bouhouch, "Fuzzy controller to extract the maximum power of a photovoltaic system", in Renewable and Sustainable Energy Conference (IRSEC), Ouarzazate, Morocco, 7-9 March 2013, pp. 141 - 146.

[16] B. Alajmi, K. Ahmed, G. Adam, and B. Williams, "Single Phase Single Stage Transformer less Grid Connected PV System" in IEEE Transactions on Power Electronics, Vol. 28, No. 6, June 2013, pp. 2664-2676.

[17] M.A.A. Mohd Zainuri, M.A.Mohd Radzi, A.C.Soh, and N.A. Rahim, "Development of adaptive perturb and observe-fuzzy control maximum power point tracking for photovoltaic boost dc-dc converter," Renewable Power Generation (IET), vol. 8, no.2, March 2014, pp. 183 - 194.

[18] S. Kang, J. Ko, "A Novel MPPT Control of Photovoltaic System Using FLC Algorithm", 11th International Conference on Control Automation and Systems (ICCAS), Korea, 2011 pp. 434-439.

[19] M. Addel-Geliel1 and A. Khalil "Adaptive Fuzzy Controller for Loop Control in a Distributed Control System" 17th Mediterranean Conference on Control and Automation (MED), 9(2), Greece, June 2009, pp. 55-60. 